Gender pairing variations in peer tutoring: The case of senior high school students in Eastern Visayas, Philippines

Gacosta, Ma. Lorina $\bigotimes$

Kananga National High School, Philippines (gacostaml13@gmail.com)

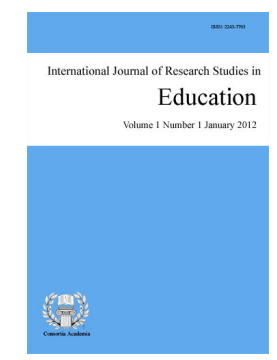

Accepted: 17 January 2022 Online ISSN: $2243-7711$

OPEN ACCESS

\title{
Abstract
}

This study focused on the effect of gender variations in peer tutoring on the Senior High School Grade 11 students of Anahaway National High School in Eastern Visayas, Philippines during the second semester for the school year 2017 - 2018. The study employed a descriptive and comparative research design to find out the effect of pairing through gender variations on the scores of students in Statistics in a peer teaching relationship. The female tutees had the highest score in the level of achievement test when paired with male than paired with the same sex. There is no significant difference in the achievement level among the four combinations regardless of their gender, though, the female tutees showed the highest scores when paired with male. Peer tutoring must be used as an alternative method in enriching the learning process of the students in order to increase their interest in the subject assisted by their peers. Peer tutoring should be taught to both student-teachers and serving teachers through workshops and seminars to enable them to acquire the knowledge and use it to improve academic performance of students with specific learning disabilities, low achiever students as well as high achiever students.

Keywords: gender pairing, peer tutoring, gender variations, academic performance, tutor-tutees 


\section{Gender pairing variations in peer tutoring: The case of senior high school students in Eastern Visayas, Philippines}

\section{Introduction}

Mathematics has been defined as bedrock for technological advancement, and development for all nations. This leads to the suggestions of its teaching in a more practical way starting from the primary school level (Tella, 2013). There are initiatives to improve mathematics education, teachers' need to attend in-service trainings, mathematics workshops and seminars. In education, as in any other fields of human endeavor, mathematics is indispensable. This is considered a difficult subject to some teachers whose field is not mathematics while some students usually have a negative attitude towards the subject (Mendoza, 2005).

Ezengwu as cited in Abdullahi (2012) said that majority of teachers in the field still employ conventional methods in the classroom teaching, these methods though not without some advantages are found to be didactic, stereotype, ineffective and non-result oriented. According to Maheady (2001), peer tutoring allows teachers to accommodate a classroom of diverse learners including students with learning disabilities. This instructional strategy increases response opportunities for students, provides additional time for positive feedback, and increase the amount of a student is on-task. According to Anselm as cited by Abdullahi (2016), stated that to continue to progress in mathematics achievement, the quality of mathematics instruction must be improved in all secondary levels. Although many factors affect a student's mathematics learning, one factor over which schools have the most immediate control is the choice of mathematics program to be implemented by teachers, administrators and curriculum developers.

Peer tutoring is designed as method of teaching new skills. It provides all students the opportunity to grow academically, however, the question remains as to what strategies are appropriate to achieve the desired goals. In some instances, peer tutoring is considered to assist students achieved learning. (Hott et al., 2012). Gender is one of the personal variables that have been related to differences found in motivational functioning and in self-regulated learning. Different research has demonstrated the existence of different attribution patterns in boys and girls, such that while girls tend to give more emesis to effort when explaining their performance boys appeal more to ability and luck as causes of their academic (Ghazvini \& Khajehpour, 2011).

In the National Performance of High School Students in the National Achievement Test (NAT) shows that there is a decrease in the performance in Mathematics of students from School Year 2015-2016, 2014-2015 and 2011-2012 which is 46.37, 47.82 and 50.70, respectively. The result may be brought to student's lack of appreciation on the subject which might need reinforcement in order for them to love and appreciate the subject. The researcher decided to conduct this study in order to establish a baseline data on the importance of adopting peer tutoring as a reinforcement in making mathematics students understand, love and appreciate mathematics leading to a better performance in the subject and more importantly on the performance of students in National Competency Examinations.

\subsection{Statement of the Problem}

This study aimed to determine the effectiveness of gender pairing variations in peer tutoring in Statistics of Grade 11 students. It sought to answer the following questions:

$>\quad$ What is the level of achievement test of student- tutees exposed to gender pairing variations, male and female, male and male, female and female, and female and male?

$>\quad$ Is there a significant difference in the level of achievement test in Statistics among the gender pairing 
Gender pairing variations in peer tutoring: Case of senior high school students in Eastern Visayas, Philippines

variations of student-tutees?

$>\quad$ Which among the gender tutoring pairing variations has the highest level of achievement test in

Statistics?

\subsection{Scope and Delimitation}

This study focused on the gender pairing variations in peer tutoring. The Grade 11 Senior High School Students of Anahaway National High School, Palo, Leyte was the respondents of the study. The school and respondents were chosen since the researcher is currently connected in this school as Mathematics Teacher. The direct interaction with the students and other group of learners in the said institution formed one rationalization for the selection of this research locale. In the study, there were thirty-two (32) participants with sixteen (16) groupings and four (4) groups for each gender pairing variations. The experiment was conducted in a classroom setting and was grouped according to their gender pairing variations.

\section{Cited Literatures and Studies}

The inclusion of the mathematics curricula raised emphasis around the importance of teaching and understanding mathematical transformations (Jones, 2002). The teacher guides and directs tutor to share his/her knowledge and experiences on an issue, learning tasks, etc. selection of tutor by the teacher is based on two criteria: (1) the tutor must demonstrate sufficient knowledge of the content to assist their low achieving partner with mathematics learning tasks; (2) the tutor must possess the quality of promoting low achievers to participate actively in the learning task, wait for tutee to attempt a problem independently before offering assistance, encouragement and correct responses (Walberg \& Susan, 2000).

Reciprocal peer tutoring is a collaborative learning strategy in which students alternate between the role of tutor and tutee. Unlike the previous peer tutoring strategies discussed, RPT may involve more than a one-to-one relationship. Students alternate roles while in pairs or groups, (William et al., 2003). According to research on same-age and cross-age peer tutoring, significant gains were made in learners of all backgrounds (Cairo \& Craig, 2005). Nebo stated as cited by Abdullahi (2012) that this conventional method of teaching has failed to recognize the uniqueness of the inquiry base nature of Mathematics and the learner's individuality thus failed to encourage creative thinking in the learner leading to poor achievement of students. Based on this educators and scholars are challenged to seek for an intervention or innovative methods that would enhance academic achievement of students in Mathematics some of these methods includes concept mapping, discovering method, co-operative learning, target task approach, peer tutoring.

Hartman said as cited in Coenen, (2002), suggested peer tutors should possess leadership skills and a sense of responsibility. Tutors are expected to be able to explain the concepts of the subject being reviewed and have the ability to pique the interest of the tutee about the subject matter. Bond and Castagnera (2006), indicated peer tutoring is a small-scale society because students must learn to work together. Therefore, benefits went beyond individual students or schools, positively impacting society as a whole. Coenen (2002) reported that one-on-one teaching also allowed tutees to proceed at their own pace and permitted better understanding of material. Additionally, peer tutoring was reported as a low-cost method to address academic concerns (The Access Center, n. d.).

The reason behind the idea of peer tutoring is that it is assumed that most students working in pairs may learn better in social context. Execution of peer tutoring method takes the following procedures: (1) identification of learning tasks; (2) analysis of learning task; (3) presentation of the learning task to the whole class by the teachers; (4) selection of peer tutors; (5) briefing assigning tasks to the tutors; (6) pairing of tutor with tutees; (7) discussion of tutors with tutees;(8) monitoring of peer activities throughout the activity and 
provision of clue; (9) teacher process feedback for incorrect responses and praises for correct answers and appropriate cooperation; (10) teacher guide conclusion (Tella, 2013). Similarly, teamwork actions involve everyone in (1) understanding the whole process and its goals, (2) understanding their individual roles in the process, (3) communicating openly and regularly with one another, and (4) having joint responsibility to execute, as well as continuously improve, the process (Woods, 2007).

The following are the different studies on gender pairing variations in peer tutoring reviewed by the researcher and considered as related to the present study:

The study of Ling (2008), investigated the effect of peer tutoring on interest in mathematics, perceptions of instructional method and mathematics self-efficacy. The findings also suggest that female students performed better than the male students in mathematics achievement. The students in peer tutoring groups showed higher interest in mathematics and have higher mathematics self-efficacy. The students showed more positive perceptions toward peer tutoring compared to the traditional instruction method. In the peer tutoring group, female students showed higher interest in mathematics than males students. However, gender differences were not evident for mathematics self-efficacy and perceptions toward peer tutoring.

According to Acidre, (2012) the male group obtained a very satisfactory performance in the Mathematics achievement compared to female and mixed groups; gender grouping does not have an effect on students' mathematics achievement. All lessons in Mathematics may be not taught and learned effectively through cooperative learning gender grouping and the performance of the students in the formative test was satisfactory for both all-male and female groups, and fair performance for the mixed group. While a very satisfactory performance was obtained by the male and female groups in cooperative outputs and satisfactory performance for the mixed group; gender grouping was effective on the performance of the students in terms of cooperative learning outputs than mathematics achievement and formative tests.

The study examines gender differences existing in various cognitive motivational variables (locus of control, academic self-concept and use of learning strategies) and in performance attained in school subjects of Literature and Mathematics. For this purpose, a sample of 363 students was selected from the high school students in the first, second and third academic years. For achieving to the purpose used of locus of control questionnaire, self-concept questionnaire and LASSI. Results show the existence of gender difference in variables under consideration, with girls showing internal locus of control, using attitude, motivation, time management, anxiety, and self-testing strategies more extensively, and getting better marks in Literature (Ghazvini, Khajehpour, 2011).

Draper (2004), examined the gender grouping (single - gender vs. mixed - gender) in cooperative learning structures, as well as the interaction of the structure on the educational activity. Based on gender groupings, DeBarthe discovered that while man showed no differences in learning between the control and experimental groups, women did exhibit slightly higher levels of learning in the latter. Results also revealed that females in mixed - gender groups, including cooperation, competence learning structures do benefit females.

In the study conducted in Brown University, women perform as much as 12 percent better on math problems when tested in a setting without men. Further they added that the presence of men can interfere with women's problem-solving performance because anxiety can distract someone from taking an exam (Science Daily, 2000).

\subsection{Theoretical Framework}

In the study of Vygotsky, the concept of learning through peer tutoring is based on a social constructivist view of learning that emphasis students to generate learning where students coach peers thorough social interaction within zone of proximal development (Vygotsky, 1978). Rather than applying a stimulus/response process, users are actively engaged in making meaning through cognitive accommodation and/or assimilation (Piaget, 1969). Vygotsky argued that learning comes about through social negotiation within cultural context, with languages as the primary enabling tool. This social constructivist philosophy has been expanded on recently,

56 Consortia Academia Publishing (A partner of Network of Professional Researchers and Educators) 
introducing the notion of cognitive apprenticeship through which students learn in a manner similar to traditional apprenticeships. The students access expertise through mentors, whose role is to facilitate rather than teach, and the aim of learning is to solve mathematical problems in authentic setting. For a gender pair in peer tutor, this setting is a very realistic human setting. The argument is that students are better equipped to approach non familiar problems and produce solutions that are appropriate to a given culture. Peer tutoring is aligned with these aspects of social constructivist theory by enhancing social negotiation with the student tutor and tutee, where knowledge construction is promoted through communication and dialogue, which is helpful for the tutee.

According to Vygotsky (1978) as cited in Clarkson and Luca (2002), much important learning by the child occurs through social interaction. He views interaction with peers as an effective way of developing skills and strategies. He suggests that teachers use cooperative learning exercises where less competent children develop with help from more skillful peers - within the zone of proximal development. He emphasized the importance of social interaction in the learning process when he stated that "every function in the child's cultural development appears twice: first, on the social level, and later, on the individual level; first, between people (inter-psychological), and then inside the (intra-psychological)". From social constructivist theory, the learner characteristics were selected as a set of independent variables which assumed to affect the student performance in Statistics through gender pairing variations in peer tutoring. It is assumed, based on the tenets of the aforementioned theories that gender pairing variations in peer tutoring between the high - low learners are associated to their innate characteristics of gender pairing variations. The operationalization of this theoretical in manifested in the conceptual framework shown in the succeeding page.

The study is also anchored on the theory on individual differences, the theory of compensation. Theory compensation or negative correlation states that weakness in one trait is compensated by strength in other traits. Males and females are different. Males have 10 to 15 percent larger brains than female (Jensen, 2008). She enumerated the gender differences in performing skills and tasks

\subsection{Conceptual Framework}

Figure 1 shows the conceptual framework of the study, which was based on the theoretical assumptions presented earlier in this section. As seen in the figure, the research described the level of achievement test of students exposed to gender pairing variations. The study also described the significant difference in the level of achievement test in Statistics among the gender pairing variations of student-tutees.

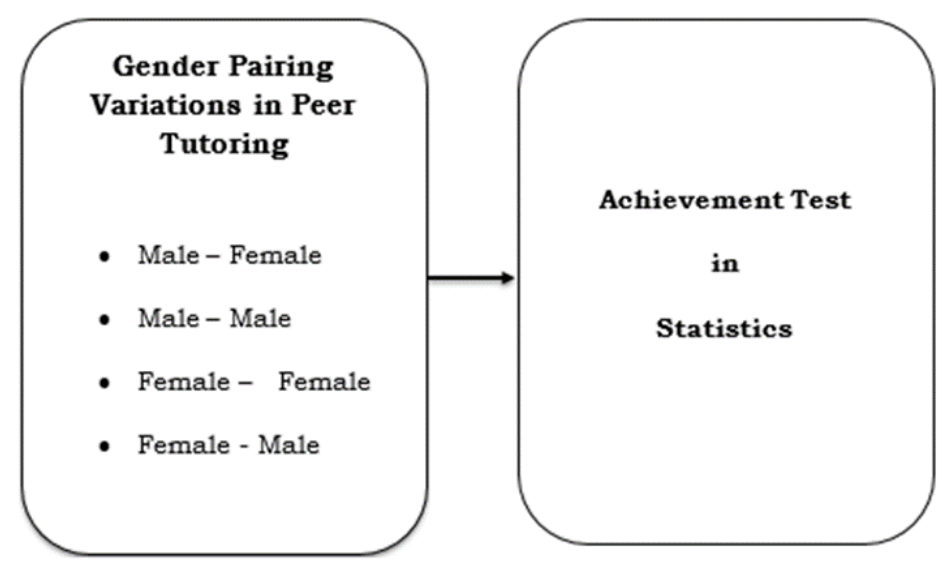

Figure 1. The Conceptual Framework of the Study on the Gender Pairing Variations in Peer Tutoring

\section{Methodology}

The study employed a descriptive and comparative research design to find out the effect of pairing through 
gender variations on the scores of students in Grade 11 Statistics in a peer teaching relationship. Gender pair variation: male - male, male - female, female - female, and female - male x Assignment: tutors - male or female, tutees - male or female (with fixed assignment for tutors - have high learning ability, tutees - have low learning ability, with four pairs each on pairing variation.

The study used the analysis of variance (ANOVA) to test the difference among the groupings in the level of achievement test in Statistics in the gender pairing variations of student-tutees. The respondents of the study were the Grade 11 students from the two (2) sections of Anahaway National High School in Eastern Visayas, Philippines during the school year 2017-2018. Thirty-two (32) students were chosen as participants composed of 16 groupings and four (4) groups each of gender variations. Sixteen (16) acted as tutors who belonged to the top 8 males and 8 females that were chosen based on their previous grade in Statistics during the midterm period of the second semester of the school year 2017 - 2018. Another sixteen (16) tutees (8 males and 8 females) was also chosen based on their previous Statistics grade during midterm period ( 80 and below grades). The regular students who were not part of the study was also paired together and take the same worksheets, quizzes and achievement test for teacher records.

The researcher utilized a research-made achievement test and undergone validation was used in gathering the necessary data that determined the performance of students in Statistics who underwent gender pairing variations in peer tutoring. The research instrument was composed of a 30-item test based on the topics covered in the fourth quarter. It is a multiple-choice type of test with four options. To ensure the validity of the achievement test, the researcher constructed table of specification, submitted a copy for evaluation to the researcher's adviser, panelists and conducted a dry-run to the selected 'grade 12 students of San Joaquin National High School, Palo, Leyte. After the dry-run, the results were tallied, evaluated, and analyzed in terms of index of discrimination, index of difficulty and quality of distracters. The achievement test was tested for its reliability using the Kuder - Richardson Formula 20. The reliability coefficient was 0.815 which indicated that the test was reliable.

\section{Findings}

\subsection{Level of Achievement of Students Exposed to Gender Variations in Peer Tutoring}

The students exposed to gender pairing variations in peer tutoring underwent an achievement test to find out if there is any difference in their level of achievement in Statistics. Table 1 presents the results of the 30-item achievement test. It is revealed in Table 1 that the mean score for the male - female pairs with the female tutee was 18.5 interpreted as good. The result implied that female tutee performs well when they are paired with males. The peer instruction increases the social interaction among students, it affects the attitudes of the students positively. For the male - male tandem a mean score of 13 was obtained and interpreted as fair. For the female female with a female tutee had a mean of 14.75 interpreted as fair. For the female-male pairing with a male tutee had a mean score of 11 interpreted as fair. The result implies that tutees perform fairly when they are paired with same gender or when the tutee is male paired with female.

\subsection{Comparisons of the Level of Achievement between the Four Gender Pairing Variations}

Further, Table 1 can be observed that the female tutees got the highest level of achievement when paired with male than pairing them with the same gender. Whereas, female tutees got lesser differences when paired with the same gender. The result implied that female tutees best performs well when being paired with male.

\subsection{Difference in Gender Pairing Variations and Level of Achievement}

To find out if there is any difference in the level of achievement in Statistics of Grade 11 students of Anahaway National High School in terms of gender pairing peer tutoring variations, the analysis of variance was

58 Consortia Academia Publishing (A partner of Network of Professional Researchers and Educators) 
performed with the scores as the dependent variable while the gender pairing variation as the independent variables. Table 2 presents the results of this statistical analysis. Data in Table 2 revealed that the computed $p$ values for the comparisons of the scores of students achieved in Statistics of Grade 11 students of Anahaway National High School are above the 0.05 significance level for the gender pairing variation. This means that there is no significant difference in the scores achieved by students in the four different combinations.

Table 1

Results of the Achievement Test

\begin{tabular}{lcccc}
\hline \multicolumn{1}{c}{ Gender Variations/Dyad } & Pair & Scores of & Mean & Interpretation \\
\hline \multirow{3}{*}{ Male - Female } & 1 & 17 & & Good \\
& 2 & 18 & 18.5 & \\
Male - Male & 3 & 22 & & Fair \\
& 4 & 17 & 13 & Fair \\
Female - Female & 1 & 15 & & \\
& 2 & 12 & 14.75 & \\
Female - Male & 3 & 16 & & Fair \\
& 4 & 13 & & \\
\end{tabular}

Table 2

Difference in the Level of Achievement Among Gender Pairing Variations

\begin{tabular}{cccc}
\hline Source of Variation & Foalue & $p_{\text {value }}$ & Interpretation \\
\hline Pairing & 2.538 & 0.106 & Not Significant \\
\hline *Significant at 0.05 level & & &
\end{tabular}

The male - female combinations showed highest scores while the male - male dyads obtained the least scores among the four combinations. Furthermore, it is also observed that there is no significant difference in the scores between the tutees in the different parings wherein obviously, which means the result of the achievement test of tutees are the same or almost near with each other. Therefore, the null hypothesis stating that there is a significant difference in the level of achievement in Statistics of Grade 11 students among the gender pairing peer tutoring variation is rejected. Nevertheless, there are still other factors that may affect academic achievement of students independent of gender. Such factors may include social, economic, medical/health, familial, relationships between teachers and students, and school expectation.

\section{Conclusions}

The study focused on the Gender Pairing Variations in Peer Tutoring. Thus, based on the findings of the study it concluded that Female tutees got the highest score when paired with male than pairing them with the same sex in the level of achievement test of student-tutees in the gender pairing variation, while the female tutees got a lesser difference when paired with same sex. There is no significant difference in the achievement level among the four combinations regardless of their gender. Though, the female tutees showed highest scores when paired with male and the male obtained the least scores when paired with male among the four combinations, the result showed that their score where almost the same or near with each other. Among the gender pairing peer tutoring variations, the female tutees have the highest level of achievement in Statistics when paired to male which showed to be effective combination in peer tutoring. 


\subsection{Recommendations}

Based on the conclusions drawn in the study, the following are hereby recommended that in gender pairing for peer tutoring, female tutees maybe paired with male considering that they perform well and not of the same gender considering that they perform less. Peer tutoring maybe used as an alternative method in enriching the learning process of the students in order to increase their interest in the subject assisted by their peers. It is recommended that peer tutoring maybe taught to both student-teachers and serving teachers through workshops and seminars to enable them to acquire the knowledge and use it to improve academic performance of children with specific learning disabilities, low achiever students as well as high achiever students. It is also recommended that a similar study will be conducted where tutees will be allowed also to act as tutors to determine its effect on gender pairing variations.

\section{References}

Abdullahi, I. (2013). Effect of peer tutoring teaching strategy on secondary school students' academic achievement in mathematics, Kwara State, India.

Acidre, M. (2012). Cooperative learning gender grouping and students Achievement in Mathematics. Unpublished Master's Thesis, Eastern Visayas State University, Tacloban City.

Bond, R., \& Castagnera, E.(2016). Peer supports and inclusive education: An underutilized resource. Netherlands.

Clarkson, B., \& Luca, J. (2002). Promoting students learning through peer tutoring. Edith Cowan University.

Coenen, M. D. (2002). Using gifted students as peer tutors. Gifted Child Today, 25(1), 48-58.

Draper, S. (2010). The effects of gender grouping on student curiosity in modular technology education laboratories. Technology and Engineering.

Drapper, S. R. (2004). The effect of gender grouping and learning style on the student curiosity in modular technology education laboratories. Virginia.

Ezenwosu, S. U., \& Nworgu, L. N. (2013). Efficacy of peer tutoring and gender on students' achievement in biology. International Journal of Scientific and Engineering Research, 4(12), 944-950.

Ghazvini, S., \& Khajehpour, M. (2011). Gender differences in factors affecting academic performance high school students. Islamic Azad University.

Hott, B., Walker, J., \& Mason, J. (2012). Peer tutoring. Jasneen Sahni, Marymount University.

Jensen, E. (2008). Brain-based learning: The new paradigm of teaching. SAGE Publications.

Ling, G. (2008). The effectiveness of peer tutoring in teaching of straight line. University Malaysia, Sarawak.

Little, D., \& Walker, B. (1968). Tutor-pupil relationship and academic progress. Personnel and Guidance Journal, 47, 324-328.

Meheady, L. (2001). Peer-mediated instruction and interventions and students with mild disabilities. Pennsylvania State University.

Mendoza, N. (2005). Correlates of academic performance in mathematics of secondary school students in Leyte Division: Inputs to an intervention science. Unpublished Master Thesis, Eastern Visayas State University Tacloban, City.

Musa, J., Dauda, B., \& Umar, M. (2016). Gender differences in achievement goals and performances in English language and mathematics of senior secondary school students. Borno State, Nigeria.

Obidoa, M. A., Eskay, M., \& Onwubolu, C. O. (2013). Remedial help in inclusive classrooms: Gender differences in the enhancement of mathematics achievement of students through PAL (Peer-Assisted Learning). US-China Education Review, 3(3), 172-180.

Oviawe, J. I., Ezeji, S. C. O. A., \& Uwameiye, R. (2015). Comparative effects of three instructional methods on students' performance in building technology in Nigerian polytechnics. European Scientific Journal, 11(12), 274-285.

Tella, A. (2013). The effect of peer tutoring and explicit instructional strategies on primary school pupils learning outcomes in mathematics. University of Ibadan, Nigeria. 
Gender pairing variations in peer tutoring: Case of senior high school students in Eastern Visayas, Philippines

Walberg, H. J., \& Susan, J. P. (2000). Effective educational practices. Chicago: International Academy of Education.

Woods, T. (2007). Motivating faculty through transactional and transformational leadership strategies. Journal of Leadership Studies.

https://courses.lumenlearning.com/boundless-management/chapter/defining-teams-and-teamwork/ 
Gacosta, M. L.

62 Consortia Academia Publishing (A partner of Network of Professional Researchers and Educators) 